\section{Trouble at Rome University}

SIR-We would like to bring to the attention of the international scientific community the situation at the faculty of medicine of the University of Rome 'La Sapienza'.

This school of medicine, one of the largest in the world, has more than 10,000 students and a teaching staff of over 800 , consisting of about 200 full professors and 600 associate professors, all of them with tenure. Unfortunately, the scientific output of this conspicuous institution is far from adequate for its size. The annual production of papers in international refereed journals averages 80 ; that is, 0.1 per faculty member. At a time of vigorous growth of new and promising directions of biomedical research, such a mediocre level of scholarly activity is startling, and this situation reflects a lack of involvement in research for most of the faculty members, perhaps as a consequence of their high mean age (over 50 for associate professors).

This situation might have been partially remedied by the appointment of younger staff, better trained and more keen on research. Indeed, every few years (generally four) the government asks the faculties to plan their development in terms of new teaching positions. In this context, a four-year plan including proposals for new positions of associate professor was to have been presented to and voted on by the majority of the faculty members no later than March 1989. But the faculty of medicine in Rome has succeeded in postponing any decision for over a year, and has recently decided, uniquely among all the Italian faculties, to renounce the appointment of new associate professors, including those proposed from a list of candidates who have spent at least three years at distinguished foreign research institutions. This negative decision was taken in opposition to the recommendations forwarded by the departments and institutes.

We feel that blocking the appointment of new staff members at associate professor level will result in strangling the development of new research areas and worsening the scientific and teaching stature of this school of medicine at a time when the international scientific community is vigorously expanding in new research directions in the field of biomedicine.

This destructive opposition was promoted by a group of associate professors who hold as hostage the appointment of new associate professors, regardless of teaching necessities and research development, until the global number of full professors approaches that of associate professors. The latter result is to be obtained by a sort of qualification test which would promote the present associate professors to full professors, and automatically confirm their tenure at Rome.

This self-interested behaviour testifies to a short-sighted view of the future of medical and basic science, and will soon produce a sclerotic institution no longer able to cope either with teaching needs or with the quality standards of the scientific community. This attitude sacrifices the scientific growth of the faculty to the career expectations of its members and is in line with the archaic faculty tradition which has in the past resulted in favouring an internal member of the faculty over the Nobel laureate Dr Bovet.

We believe that something should be done to change this anticultural and narrow-minded approach. Denouncing this situation is a duty to the scientific community at large and even more to the young and qualified researchers whose prospects of contributing to biomedical research and teaching in Rome are being frustrated

PAOLO Amati

(Professor of Genetics) Piero Cammarano (Professor of Biology) ANTONIO FANTONI (Professor of Genetics) GIUSEPPE MACINO

Faculty of Medicine,

(Professor of Cell Biology)

University of Rome 'La Sapienza', 00161 Roma, Italy

\section{Testing criteria}

SIR-The implication in your leading article (Nature 343, 494; 1990) regarding the toxicity and efficacy tests for genetically engineered 'drug' products, that such products need not be subjected to the rigorous criteria applied to chemically synthesized drugs because "they are intended to be identical with those produced naturally in normal human beings", should not be allowed to pass unchallenged.

The intention and the outcome of any process are frequently very different and a number of problems can be envisaged in the case of genetically engineered substances.

Besides contamination from constituents of the culture, used in their production, having properties that preclude their separation from the product, a far more serious problem could arise from errors during the synthesis and replication and/ or the misreading of the recominantDNA. The products of such events - a single amino-acid substitution due to a single base change in the DNA or an alteration in a peptide sequence due to a frame-shift type mutation - could result in serious side effects such as an alteration in the nature of the activity, for example antagonist rather than agonist activity and/or, the acquisition of immunogenicity by the altered product that would crossreact with the "products produced naturally in normal human beings" leading to an autoimmune reaction.

Rather than being "over-rigorous", it would be more prudent to ask whether the tests applied are the correct tests for such products and are sufficiently rigorous.

I. ab |. DAVIES

School of Pharmacy,

The Queen's University of Belfast, 97 Lisburn Road, Belfast BT9 7BL, UK

\section{Big guns}

SIR - That which has been thought about has been, is being or will be tried out, particularly on the wilder shores of defence science. Both your comments on 'big gun' technology and the free-ranging thoughts of Daedalus (Nature 344, 811 \& $820 ; 1990$ ) have been witness to this.

Some 30 years ago when studying the storage of high-pressure air in chalk caverns, I was discreetly approached to comment on the feasibility of a deep shaft to house a giant multi-stage air gun - a British rival to HARP. A decade later, I used a designed sequence of explosive impulses to liquefy sand. Such impulses designed along Daedalus lines have been used to test full-scale structures for their response to earthquakes. True novelty is rare.

Soil Mechanics Associates Limited, Glossop House, Hogwood Lane, Finchampstead, Wokingham,

Berkshire RG11 4QW, UK

\section{Weight of culture}

SIR-Nature suffers from tunnel vision in smugly condemning Americans for preferring the British system of weights and measures (Nature 344, 575; 1990). This attitude fails to appreciate that units of measurement are not merely calculating devices, but integral components of a nation's cultural matrix. As such they are the numerical equivalents of the languages, traditions and customs that identify and enrich us both collectively and as individuals

The ineluctable march of the metric system represents the victory of cold calculation over the ebullience of the human spirit. Once its triumph is complete, the world's cultural gene pool will have become further depleted and humanity reduced one more step towards the mentality of the average robot.

Blackheath Grove,

C.H. Evans

London SE3 ODH, UK 